\title{
Prevalence, perceptions and practices associated with non-adherence to diabetes medications in primary care setting: A cross sectional study in urban Bangalore
}

\author{
Leeberk Raja Inbaraj', Carolin Elizabeth Georg', Nan Lin Kham², Gift Norman³ \\ ${ }^{1}$ Consultant, Division of Community Health, Bangalore Baptist Hospital, Karnataka, India, ${ }^{2} \mathrm{MNCH}$ Coordinator, Shan \\ Development Foundation, Shan State, Myanmar, ${ }^{3} \mathrm{Head}$, Division of Community Health, Bangalore Baptist Hospital, \\ Bengaluru, Karnataka, India
}

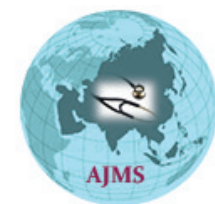

\section{A B S T R A C T}

Background: Adherence to diet and drugs, blood glucose monitoring, foot care, exercise and early recognition of the complications, are the crucial elements for tertiary prevention of Diabetes Mellitus. Non compliance can lead to poor glycemic control which can eventually aggravate complications and lead to disability and mortality. Aims and Objective: This study aimed at estimating prevalence of non-adherence and identify perceptions and practices associated with non-adherence. Materials and Methods: A cross sectional study was conducted in a primary care clinic in a disadvantaged community hundred patients with Diabetes were recruited and interviewed using a semi-structured questionnaire. Results: Non adherence rate was $30 \%$. Those who are unable to remember multiple doses $(37.5 \%)$ were 2.77 (95\% Cl: 0.94-8.15) times more likely to non-adhere to the treatment than those who are able to remember multiple doses $(16.7 \%)$. Similarly patients who often discontinued medications and switched over to alternative system medicines tended to be non- adherent 8.5 (95\% Cl:1.6- 45.0) times more than those who continued treatment without interruption. Non adherence was not associated with age, gender, education level, and cost of medication and duration of diabetes. People who were illiterate and elderly did not know the consequences of missing doses and stopped medications when they felt better as well as resorted to traditional medicines. Conclusions: Counselling sessions should focus on perceptions and ideas about diabetes. Innovative health education modalities have to be developed for illiterate and elderly people.

Access this article online

Website:

http://nepjol.info/index.php/AJMS DOI: 10.3126/ajms.v7i6.15256 E-ISSN: 2091-0576 P-ISSN: 2467-9100

Key words: Non adherence, Diabetes mellitus, Perception, Forgetfulness

\section{INTRODUCTION}

According to the World Health Organization (WHO), adherence is the extent to which the patient follows medical instructions, takes medication, follows a prescribed diet and sticks to lifestyle changes which corresponds with recommendations from a health care provider. ${ }^{1}$ Adherence to diet and drugs, blood glucose monitoring, foot care, exercise and early recognition of the complications, are the crucial elements for tertiary prevention. Non compliance can lead to poor glycemic control which can eventually aggravate complications related to Diabetes Mellitus which will in turn increase direct and indirect cost to the healthcare system. ${ }^{2}$ The objectives of this study was done to determine the non- adherence rate to pharmacological therapy and to identify perceptions and practices associated with non-adherence among patients with type 2 diabetes in a primary health care clinic of Bangalore. 


\section{MATERIALS AND METHODS}

A cross-sectional study was conducted at a primary care clinic in a disadvantaged community managed by Bangalore Baptist Hospital between March 2015 to June 2015. Diabetic patients who were more than 30 years of age with at least a one-year history of diabetes, and who were on pharmacological therapy for the last six months, were recruited by convenient sampling technique. Pregnant women and those who presented with serious illness requiring admission or referral were excluded. As per the study done in India, non-adherence rate was taken as $70 \%$, and using the formula $4 \mathrm{PQ} / \mathrm{D}^{2}$ the sample size was calculated as 84 (d-10), however 100 patients were included in the study. ${ }^{3}$ The interviewer administered a structured questionnaire to collect data. The questionnaire had three parts which included the demographic profile, Morisky's Instrument to measure the rate of non-adherence and the final part to assess factors and perceptions associated with non- adherence. Patients were asked to agree or disagree to 9 statements which indicated their attitude and practice regarding diabetes care.

- If the drug was provided free of cost I would have taken it more regularly

- I feel dietary restriction was difficult to maintain

- I think self monitoring of glucose is cumbersome

- I find it difficult to take too many drugs

- I am not aware of consequences of missing doses

- I am not able to remember too many doses

- I think there are side effects with medications

- I often discontinue the prescribed medications on my own and switch over to alternate medicine.

Morisky's Instrument has high reliability and validity, and the patient was considered to be adherent if they answered in the negative to all four questions. ${ }^{4}$ BMI and recent fasting (FBS) or post prandial blood sugars (PPBS) were also recorded. Being engaged in a physical activity of moderate intensity for 3-5 days a week was considered as compliance to physical activity. A patient was considered to be compliant to his/her diet, if they had reduced the quantity and increased the frequency of vegetables and fruits intake after the diagnosis and was following it at least 3-5 days a week. Data was entered in MS-Excel 2003 and analyzed by using the SPSS for Windows (Statistical Package for Social Sciences) version 17.0. The findings were expressed in terms of proportions. Chi-square test was used to study the association between socio-demographic factors, perceptions with compliance. A $\mathrm{p}$ value less than or equal to 0.05 was considered as statistically significant. This study was approved by Institutional Review Board of Bangalore Baptist Hospital.
Informed consent was obtained from all individual participants included in the study.

\section{RESULTS}

Hundred diabetic patients were enrolled in the study. The mean age was $55.6+/-10.1$ years and majority were from the age group of 51-60 (38\%) years. More than two third of the patients were women $(63 \%)$ and most of them $(38 \%)$ were illiterate (Table 1). Mean BMI of the patients was $26.9+/-2.9 \mathrm{~kg} / \mathrm{m}^{2}$ with a significant proportion $(60 \%)$ being either obese or over-weight. More than one third $(38 \%)$ had diabetes for more than 6 years. Nearly half of the patients (47\%) were involved in semi-skilled occupation. The average monthly income was Rs. 8727.2/month, which ranged from 2000-25000. The average money spent on medications was Rs. $345.98 \pm 173.6 /$ month. Diabetic patients were spending an average of $4.7 \%$ of their monthly income on medications. A quarter $(24.3 \%)$ of the males were smokers and $5.4 \%$ occasionally consumed alcohol. Majority of the patients were only on oral hypoglycaemic agents $(93 \%)$.

Seventy percent of the study population has responded in the negative to all 4 questions in Morisky's questionnaire (Table 2) giving a non-adherence rate of $30 \%$. Non adherence rate for non-pharmacological therapy such as exercise and diet was $41 \%$ and $49 \%$ respectively.

More than a third (34\%) exercised (brisk walking for half an hour) 5 days a week. Almost half (59\%) of the patients modified their diet after being diagnosed with diabetes. The most common diet change reported was replacement of

\begin{tabular}{|c|c|c|}
\hline Characters & Variables & Total $(100 \%) \mathrm{N}=100$ \\
\hline \multirow[t]{5}{*}{ Age in years } & $30-40$ & 7 \\
\hline & $41-50$ & 28 \\
\hline & $51-60$ & 38 \\
\hline & $61-70$ & 23 \\
\hline & $>70$ & 4 \\
\hline \multirow[t]{2}{*}{ Gender } & Male & 37 \\
\hline & Female & 63 \\
\hline \multirow[t]{4}{*}{ Educational status } & None & 38 \\
\hline & Primary & 28 \\
\hline & Secondary & 12 \\
\hline & Graduation & 12 \\
\hline \multirow[t]{3}{*}{ Marital status } & Single & 2 \\
\hline & Married & 93 \\
\hline & Widow(er) & 5 \\
\hline \multirow[t]{3}{*}{ BMI } & Normal & 40 \\
\hline & Overweight & 38 \\
\hline & Obese & 22 \\
\hline \multirow[t]{4}{*}{ Duration of DM } & $<1$ & 14 \\
\hline & $1-3$ & 24 \\
\hline & $3-5$ & 24 \\
\hline & $>6$ & 38 \\
\hline
\end{tabular}


simple carbohydrates with complex carbohydrates (rice to ragi or wheat chappati) and addition of more servings of vegetables.

Many patients hoped that they will get cured in 5- 8 years. When asked how long they need to continue diabetic medications, only 60\% answered 'lifelong'.

A quarter of patients reported that they would have taken medications more regularly if they were provided free of cost. Majority $(77 \%)$ of them said that is difficult to take many medications and remember the doses correctly (70\%). 39\% were unaware of the consequences of missing doses and $88 \%$ believed that there were no side effects to the diabetic medication. A small proportion (8\%) of patients confessed that they often discontinued the prescribed medications by themselves and switched over to alternative system of medicine. Among them, 50\% were unaware of the consequences of missing medications. Most common side effect quoted by them was liver problem. Patients who often discontinued medications and switched over to alternative system medicines tended to be non- adherent 8.5 (95\% CI: 1.6- 45.0) times more

\begin{tabular}{lcc}
\hline Table 2: Morisky's instrument & $\begin{array}{c}\text { No. of } \\
\text { patients } \\
\text { who said } \\
\text { 'No' }\end{array}$ & $\begin{array}{c}\text { No. of } \\
\text { patients } \\
\text { who said } \\
\text { 'Yes' }\end{array}$ \\
\hline Questions & 83 & 17 \\
\hline $\begin{array}{l}\text { 1. Did you ever forget to take } \\
\text { your medication? }\end{array}$ & 90 & 10 \\
$\begin{array}{l}\text { 2. Were you careless at times } \\
\text { about taking your medication? }\end{array}$ & 89 & 11 \\
$\begin{array}{l}\text { 3. When you felt better, did you } \\
\text { sometimes stop taking your } \\
\text { medication? }\end{array}$ & 93 & 7 \\
$\begin{array}{l}\text { 4. Sometimes, if you felt worse } \\
\text { when you took your medicine } \\
\text { did you stop taking it? }\end{array}$ & & \\
$\begin{array}{l}\text { The number of patients who } \\
\text { said 'No' to all four questions } \\
\text { were considered adherent to the } \\
\text { prescribed anti-diabetic treatment }\end{array}$ & 70 & \\
\hline
\end{tabular}

than those who continued treatment without interruption. Non adherence was not associated with age, gender, education level, cost of medication and duration of diabetes (Table 3).

Patients who perceived that dietary restrictions were difficult to maintain were likely to non adhere to the medications than those who perceive it's easy to maintain $(48.9 \% \mathrm{Vs}$ $17.5 \%)$ and this was statistically significant $(p<0.05)$ with odd's ratio of 5.62 (95\% CI: 2.17-14.5). Those who are unable to remember multiple doses $(37.5 \%)$ were 2.77 (95\% CI: $0.94-8.15$ times more likely to non-adhere to the treatment than those who are able to remember multiple doses (16.7\%) (Table 4).

\section{DISCUSSION}

Our study revealed $30 \%$ of the patients were nonadherent to therapeutic treatment. The majority of the non-adherence was unintentional. This is much lower than the earlier study done in Divya et al in Karnataka and by Shobana et al who reported $50 \%$ and $70 \%$ non adherence rate respectively. ${ }^{5,6}$ This may be due to the improved awareness on diabetes over the years and availability of better preparations at an affordable cost in the primary care clinic and better provider-patient communication.

Forgetfulness was the most common reason for of non-adherence reported in this study population. All of them who reported forgetfulness were above 40 years and almost half $(52.9 \%)$ of them were above 60 years. Among the people who reported to be careless in taking medicines, 50\% were illiterate and an addition 30\% had only a primary education. $60 \%$ of them belonged to the age group of 61-70 years. Half of them were not aware of the consequences of missing doses.

People tend to discontinue medications when they felt better compared to worse. Majority of patients who

Table 3: Factors associated with non-adherence

\begin{tabular}{|c|c|c|c|c|c|c|c|c|}
\hline \multirow[t]{2}{*}{ Factors } & \multirow[t]{2}{*}{ Variables } & \multicolumn{2}{|c|}{ Adherence } & \multicolumn{2}{|c|}{ Non adherence } & \multirow[t]{2}{*}{ Total } & \multirow[t]{2}{*}{$P$ value } & \multirow[t]{2}{*}{ OR ( $95 \% \mathrm{CI})$} \\
\hline & & No & $\%$ & No & $\%$ & & & \\
\hline \multirow[t]{2}{*}{ Gender } & Male & 26 & 70.3 & 11 & 29.7 & 37 & 0.96 & $9.8(0.40-2.37)$ \\
\hline & Female & 44 & 69.8 & 19 & 30.2 & 63 & & \\
\hline \multirow[t]{2}{*}{ Age (years) } & $<60$ & 23 & 62.6 & 14 & 37.8 & 37 & 0.19 & $0.55(0.23-1.34)$ \\
\hline & $>60$ & 47 & 74.6 & 16 & 25.1 & 63 & & \\
\hline \multirow[t]{2}{*}{ Education } & Lower* & 61 & 70.9 & 25 & 29.1 & 86 & 0.61 & $1.35(0.41-4.44)$ \\
\hline & Higher & 9 & 64.3 & 5 & 35.7 & 14 & & \\
\hline \multirow[t]{2}{*}{ Duration of DM (months) } & $<=24$ & 18 & 66.6 & 9 & 33.3 & 27 & 0.65 & $0.8(0.31-2.08)$ \\
\hline & $>24$ & 52 & 71.2 & 21 & 28.8 & 73 & & \\
\hline \multirow[t]{2}{*}{ Cost (INR) } & $<=345$ & 45 & 73.8 & 6 & 26.2 & 51 & 0.30 & $1.57(0.66-3.75)$ \\
\hline & $>345$ & 25 & 26.4 & 14 & 35.9 & 49 & & \\
\hline
\end{tabular}




\begin{tabular}{|c|c|c|c|c|c|c|c|c|}
\hline \multirow[t]{2}{*}{ Perception and practices } & \multirow[t]{2}{*}{ Response } & \multicolumn{2}{|c|}{ Adherence } & \multicolumn{2}{|c|}{ Non adherence } & \multirow[t]{2}{*}{ Total } & \multirow[t]{2}{*}{$P$ value } & \multirow[t]{2}{*}{ OR ( $95 \% \mathrm{Cl})$} \\
\hline & & No & $\%$ & No & $\%$ & & & \\
\hline \multicolumn{9}{|l|}{ Perceptions } \\
\hline \multirow[t]{2}{*}{ Financial burden } & Yes & 52 & 70.3 & 22 & 29.7 & 74 & 0.92 & $0.95(0.3-2.51)$ \\
\hline & No & 18 & 69.2 & 8 & 30.8 & 26 & & \\
\hline \multirow[t]{2}{*}{ Diabetes is curable } & No & 33 & 66 & 17 & 34 & 50 & 0.38 & $0.68(0.28-1.61$ \\
\hline & Yes & 37 & 74 & 13 & 26 & 50 & & \\
\hline \multirow[t]{2}{*}{ Missing medications cause problem } & No & 27 & 69.2 & 12 & 30.8 & 39 & 0.89 & $1.06(0.44-2.54$ \\
\hline & Yes & 43 & 70.5 & 18 & 29.5 & 61 & & \\
\hline \multirow{2}{*}{ Diabetic medications have side effects } & Yes & 7 & 58.3 & 5 & 41.7 & 12 & 0.34 & $1.80(0.52-6.2)$ \\
\hline & No & 63 & 71.6 & 25 & 28.4 & 88 & & \\
\hline \multicolumn{9}{|l|}{ Practice } \\
\hline \multirow[t]{2}{*}{ Too many drugs } & Yes & 53 & 68,8 & 24 & 31.2 & 77 & 0.64 & $1.28(0.45-3.62)$ \\
\hline & No & 17 & 73.9 & 6 & 26.9 & 23 & & \\
\hline \multirow[t]{2}{*}{ Too many doses } & Yes & 45 & 64.3 & 25 & 37.5 & 70 & $0.05^{*}$ & $2.77(0.94-8.15)$ \\
\hline & No & 25 & 83.3 & 5 & 16.7 & 30 & & \\
\hline \multirow{2}{*}{ Switching to traditional medicine } & Yes & 2 & 25 & 6 & 75 & 8 & $0.00^{*}$ & $8.5(1.6-45.0)$ \\
\hline & No & 68 & 73.9 & 24 & 26.1 & 92 & & \\
\hline
\end{tabular}

discontinued their medications when they felt better were elderly $(63.6 \%)$ and illiterate $(83 \%$ had a schooling of less than 3 years). The educational status of the patients who discontinued the medications when they felt worse were poorer (illiterate 100\%) compared to the earlier group.

In our study, non-adherence was not associated with cost of medications. This was in contrast to the findings of the other studies. ${ }^{78}$ This may be because our setting the medications were subsidized based on the patient's ability to pay.

\section{CONCLUSION AND RECOMMENDATIONS}

The prevalence of non-adherence among diabetic was relatively low in our primary care clinic. Multiple drugs and multiple dosages along with forgetfulness resulted in nonadherence to medication. People who were illiterate and elderly did not know the consequences of missing doses and stopped medications when they felt better as well as resorted to traditional medicines. Apart from subsidising medications, innovative health education modality has to be developed for illiterate and elderly people.

\section{REFERENCES}

1. World Health Organization. Adherence to long-term therapies: policy for action: Meeting report, 2001 June 4-5. [cited 2016 Jul 21]; Available from: http://apps.who.int/iris/ handle/10665/66984.

2. Hughes $D$ and Manns B. Patient compliance with drug therapy for diabetic nephropathy. CMAJ 2000; 162(11):1553-1554.

3. Sontakke S, Jadhav M, Pimpalkhute S, Jaiswal K and Bajait C. Evaluation of Adherence to Therapy In Patients of Type 2 Diabetes Mellitus. Journal of Young Pharmacists 2015; 7(4s):462-469.

4. Morisky DE, Green LW and Levine DM. Concurrent and predictive validity of a self-reported measure of medication adherence. Med Care 1986; 24(1):67-74.

5. Shobhana R, Begum R, Snehalatha C, Vijay $V$ and Ramachandran A. Patients' adherence to diabetes treatment. J Assoc Physicians India 1999;47(12):1173-1175.

6. Divya $S$ and Nadig P. Factors contributing to non-adherence to medication among type 2 diabetes mellitus in patients attending tertiary care hospital in South India. Asian Journal of Pharmaceutical and Clinical Research 2015;8(2):274-276.

7. Mukherjee S, Sharmasarkar B, Das KK, Bhattacharyya A and Deb A. Compliance to anti-diabetic drugs: observations from the diabetic clinic of a medical college in kolkata, India. J Clin Diagn Res 2013;7(4):661-665.

8. Pascal IG, Ofoedu JN, Uchenna NP, Nkwa AA and Uchamma GU. Blood Glucose Control and Medication Adherence Among Adult Type 2 Diabetic Nigerians Attending A Primary Care Clinic in Under-resourced Environment of Eastern Nigeria. N Am J Med Sci 2012;4(7):310-315.

\section{Authors Contribution:}

LRI - Concept and design of the study, reviewed literature, statistically analyzed and interpreted, prepared the first draft the manuscript; CEJ - Conceptualized the study, reviewed the literature and involved in critical revision of the manuscript; NLK - Collected the data, data entry and reviewed the manuscript; GN - Concept and design of the study, interpreting results and critical revision of the manuscript.

Source of Support: Nil, Conflict of Interest: None. 